\title{
Gestão da Atividade e Atividade da Gestão - Gestão Como Desvio
}

\author{
Managing Activities and Activity \\ Management - Management as a \\ Deviation
}

Gestión de la Actividad y Actividad de la Gestión - Gestión Como Desviación

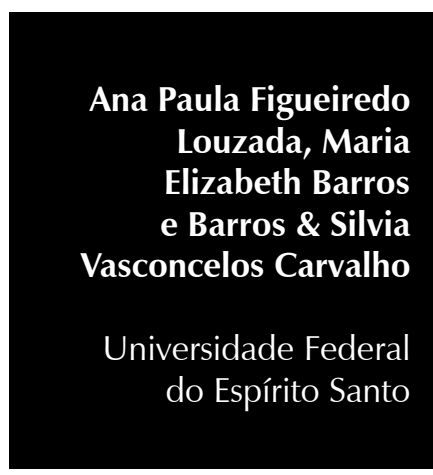

http://dx.doi.org/10.1590/1982-3703001142012
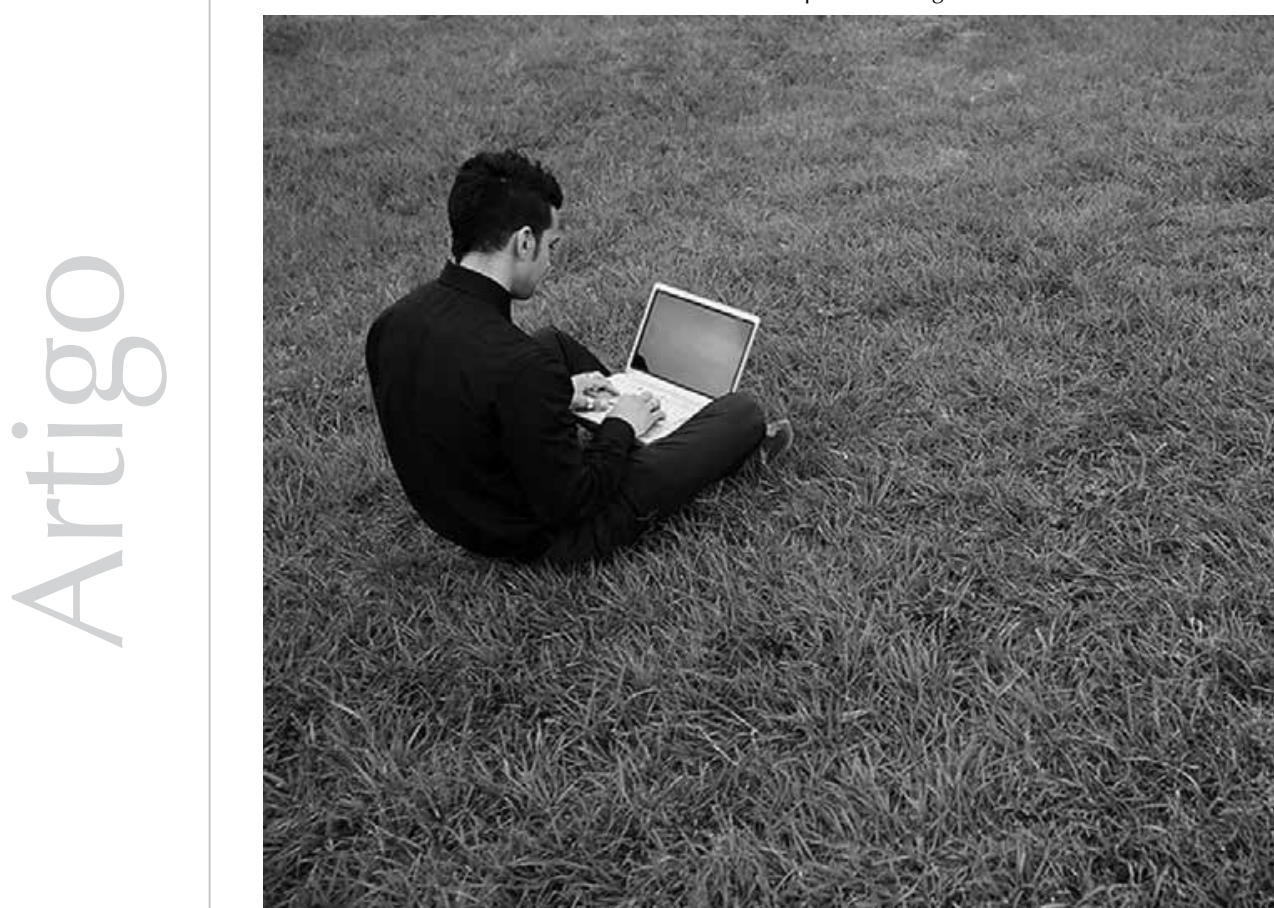
Resumo: O artigo busca fazer uma análise dos processos de trabalho dos docentes de nível superior a partir de uma posição narrativa, afirmando certa política de pesquisa. Perspectivou colocar em análise o que se produz em meio ao trabalho docente. O procedimento narrativo, mesmo partindo de um caso individual, é índice singular de situações e, como agenciamento coletivo de enunciação, não remete a um sujeito. Para compor esse exercício, traz três eixos de análise: as modulações biopolíticas impressas nos modos de trabalhar no contemporâneo; a aproximação de uma docente no exercício de seu trabalho; e a apresentação de como a invenção precisa ser pensada em meio a políticas públicas. Nesse caminho, o texto parte de algumas contribuições de $\mathrm{M}$. Foucault no que tange à análise do trabalho no contemporâneo, indicando uma importante inflexão nos modos como uma Psicologia do trabalho tem sido efetivada. A análise realizada, a partir da experiência com docentes, indica a importância de se apostar em uma gestão do trabalho como instância clínica, como desvio, que se constitui meio às relações de poder, meio à necessidade de produção de ruptura com o que está instituído em ambientes laborais hoje.

Palavras-chave: Psicologia organizacional. Trabalho docente. Biopolítica. Condições de trabalho.

\begin{abstract}
This article aims to analyze the work processes of professors from a narrative position, reinforcing a specific research policy. The goal was to analyze what is produced by faculty work. The narrative procedure, even if originated from an individual case, is the catalyst of the situations and, as a collective organizer of the enunciation, does not refer to an individual. In order to create this exercise, we brought three analysis pillars: the biopolitical modulations demonstrated in the current way of working; the approximation of a professor when performing his work; and the demonstration of how their creation must be thought in respect to public policies. In that regard, the text is based in some contributions by $\mathrm{M}$. Foucault regarding the analysis of contemporary work, indicating relevant inflection on the way occupational psychology has been applied. The analysis performed from our experience with professor, indicates the importance of investing in work management as a clinical matter, as a deviation, which is formed amidst power relationships and the need to break free from what is currently established in work environments.
\end{abstract}

Keywords: Organizational psychology. Teaching work. Biopolitics. Working conditions.

Resumen: El artículo trata de hacer un análisis de los procesos de trabajo de los docentes de nivel superior desde un punto de vista narrativo, afirmando cierta política de investigación. Ha tenido como perspectiva poner bajo análisis lo que se produce en medio al trabajo docente. El procedimiento narrativo, aun partiendo de un caso individual, es índice singular de situaciones y, como gestión colectiva de enunciación, no hace referencia a un sujeto. Para componer ese ejercicio, trae tres ejes de análisis: las modulaciones biopolíticas impresas en los modos de trabajar en lo contemporáneo; el acercamiento de una docente en el ejercicio de su trabajo; y la presentación de cómo la invención necesita ser pensada en medio a políticas públicas. En ese rumbo, el texto parte de algunas contribuciones de $M$. Foucault en lo que tañe al análisis del trabajo en lo contemporáneo, señalando una importante inflexión en los modos como una psicología del trabajo ha sido llevada a efecto. El análisis realizado desde el punto de vista de la experiencia con docentes señala la importancia de la apuesta en una gestión del trabajo como instancia clínica, como desviación, que se constituye en medio a relaciones de poder y en medio a la necesidad de producción de ruptura con lo que está instituido en ambientes laborales actualmente.

Palabras clave: Psicología organizacional. Trabajo docente. Biopolítica. Condiciones de trabajo.

\title{
Um trabalho: inventar meios
}

Na última década, em especial, diferentes autores/pesquisadores, inclusive do campo da nomeada Psicologia do Trabalho, têmse voltado para a análise dos processos de trabalho com foco no modo como os trabalhadores dirigem suas atividades, colocando em destaque a invenção. Mas como entendemos invenção? Como inerente a um sujeito? Próprio dele? Relativo à inteligência, à racionalidade? Invenção como capacidade dos sujeitos tão cara aos modos de gestão capitalística? Ora, afirmamos a invenção como algo que se constitui entre vivos, como produção de estratégias criadas quando o real nos coloca à prova e é nesse sentido que consideramos este texto: como um exercício afirmativo da potência inventiva relacionada ao campo atual da Psicologia do Trabalho.

Tratamos, portanto, de invenções que, com base na herança de Canguilhem (1990), 
seriam uma tendência de renormatização do "meio de vida-trabalho". Invenções construídas frente às imprevisibilidades de um meio sempre infiel. Aqui falamos, então, de humanos em atividade e, no caso do trabalho, de atividade industriosa, que envolve sempre um "debate de normas" (Schwartz \& Durrive 2007), sendo, portanto, criação. É por meio desse processo que encontramos a dimensão da gestão do trabalho, gestão do próprio fazer, gestão da imprevisibilidade e da variabilidade do viver, do que nos desafia a inventar mundos e sujeitos em um processo de coengendramento (Teixeira \& Barros, 2009). Não partimos, então, da tese segundo a qual a impotência humana seria um vício de sua natureza (Espinoza, 2007).

Desse modo, pesquisar o trabalho no contemporâneo torna-se uma ferramenta de publicização das atividades industriosas, nem sempre visíveis, para, quem sabe, viabilizar a produção de um comum e de singularizações dos modos de trabalhar-viver. Eis o intento da pesquisa que aqui apresentamos: tomar os processos de trabalho docente, analisá-los em meio aos modos de gestão neoliberais e produzir um desvio/torção nos modos de conceber gestão como piramidal, separada daqueles que laboram, e entendida apenas como organização do processo de trabalho atrelada aos mecanismos gerenciais. Nossa tese é outra: a de que a atividade de gestão é, principalmente, o que se passa entre os vetores-dobras que constituem o processo de trabalho - sujeitos, saberes, relações de poder; gestão como atividade de invenção de modos de trabalhar que renormatizam os processos de trabalho em situação.

A palavra gestão é, habitualmente, associada à tarefa de gerenciamento dos estabelecimentos, que é a função dos que foram denominados gestores dos estabelecimentos ou das secretarias, como se aqueles que trabalham nesses estabelecimentos não os gerissem também por meio da sua atividade de trabalho.
O problema da gestão é abordado neste artigo a partir do ponto de vista da atividade, ou seja, a partir do pressuposto de que não são apenas os supervisores, diretores e gerentes que garantem a gestão dos estabelecimentos. Toda atividade envolve microdecisões e escolhas extremamente importantes para o desenvolvimento de um processo de trabalho. A atividade é lugar das dramáticas do uso de si (Schwartz, 2004), porque é o espaço de questões como as que enfrentam qualquer profissional, que no nosso caso são professoras. Como enfrentar essa exigência? Seguimos, com Schwartz (2004), afirmando que em toda atividade de trabalho se encontra uma dinâmica do uso de si por si e do uso de si por outros. A atividade é lugar de debate de normas com o meio no qual o trabalhador se insere e constitui ao trabalhar. Todo meio de trabalho é constituído por normas antecedentes que, ao serem encontradas nas situações laborais pelas professoras, geram renormalizações, até mesmo porque, sem estas últimas, o trabalho prescrito não pode ser realizado. Temos, assim, consequências dessa distância inevitável entre o prescrito e o real. Se a distância entre o prescrito e o real no trabalho é inevitável, nesse hiato, inscrevem-se as renormalizações e mesmo obedecer às normas antecedentes, já é praticar escolhas. Ao operar nos interstícios das normas antecedentes, os humanos fazem história.

A complexidade dessas renormalizações da atividade está em diálogo permanente com os diversos níveis de normas antecedentes aos quais se faz face no meio em que se opera - das prescrições mais simples presentes na tarefa às normas sociais mais complexas. Estaríamos tratando, então, de atividade de múltiplas dimensões dos humanos nas relações que o mesmo estabelece com o meio multidimensional no qual está inserido e institui ao trabalhar. As atividades 
Inquieta-nos, portanto, o modo como o trabalho se efetiva como forma de enfrentamento, de (re)sistência, de devir, ou seja: como, ao trabalhar, o trabalhador inventa outros modos de existência? se manifestam, dessa forma, convocando um espaço de valores. Temos, aqui, uma distinção importante entre gestão prescritiva e gerencial, e atividade de gestão, esta sim potencialmente inventiva, ainda que sempre em uma agonística entre o prescritivo e o normativo. Gestão como desvio do prescritivo, de forma que os processos de invenção tenham lugar, e não reduzida a uma dimensão gerencial instituída nos estabelecimentos.

Nessa direção, Michel Foucault é um intercessor importante, uma vez que indica uma direção de análise que se abre às multiplicidades. Pela análise dos discursos, das disciplinas e da subjetivação, é possível outra orientação de análise no que tange às discussões sobre trabalho no contemporâneo: do paradigma sujeito/trabalho ao paradigma subjetivação/práticas sociais, no qual o trabalho converte-se em mais um vetor de produção subjetiva.

Assim, problematizar o trabalho no contemporâneo é indagar: como acontecimentalizálo? Acontecimentalizar o trabalho é perseguir sua desnaturalização, é insistir em suas descontinuidades para propiciar a ruptura do evidente, a emergência de singularizações, conferindo uma análise das práticas que se imiscuem por entre estratégias de saberpoder, de enunciados e visibilidades que ultrapassam os esforços analíticos de suas relações de subalternização à ideologia. É tramar a urdidura sempre emergente em uma certa correlação de forças sociais (Amador \& Barros, 2011).

Foucault nos ajuda nessa tarefa de levar à radicalidade a ruptura com o paradigma sujeito-trabalho e nos indica a força de análises que não partem de abstrações ou generalizações universalizantes: importa estarmos atentos ao presente, ao que está em curso, à raridade dos acontecimentos. Logo, não se trata de abordar o trabalho na sua generalidade relativamente estável, mas, principalmente, abordá-lo com o que se mostra inesperado e que se expressa nos embates, na intercessão dos vetores que o constituem. Tomá-lo para análise a partir de situações restritivas, muitas vezes difíceis e desafiadoras. Partir do trabalho concreto, vivo, em ato, voltando nossa atenção para o que acontecimentaliza no trabalho, ou seja, para situações cotidianas imprevisíveis, que alteram e desviam o curso da atividade. Acontecimentos que nos desafiam, que interrogam as adaptações e os ajustes (Amador \& Barros, 2011).

Inquieta-nos, portanto, o modo como o trabalho se efetiva como forma de enfrentamento, de (re)sistência, de devir, ou seja: como, ao trabalhar, o trabalhador inventa outros modos de existência? Tal ethos de análise nos coloca em posição atencional ao presente, ao que estamos instituindo, ao que estamos deixando de ser e ao que estamos fazendo de nós mesmos.

Para compor esse exercício, buscamos trazer para essa conversa três eixos de análise: as modulações biopolíticas impressas nos modos de trabalhar no contemporâneo; uma aproximação de uma docente no exercício de seu trabalho, por meio da utilização de uma metodologia de análise de processos de trabalho; e a apresentação de como a invenção precisa ser pensada em meio a políticas públicas.

\section{Trabalho e gestão no contemporâneo: modulações biopolíticas}

Para tomar o trabalho como criação, no sentido de subverter as formas de trabalho já dadas e estabelecidas, acreditamos ser necessário realizar uma análise do trabalhar no contemporâneo forjando instrumentos para tal. Tomando como referência alguns 
dos últimos trabalhos de M. Foucault, analisar essa atualidade implica em proceder à desmontagem de objetos, saberes e pensamentos dados como naturais, isto é, tomar esses "falsos objetos naturais" e deixálos aparecer como efeito de um aglomerado de acontecimentos em que humanos e coisas agem e sofrem em suas relações mútuas.

Trata-se de superar as evidências que se naturalizam e que, por isso, se apresentam como em um eterno presente, e de produzir interferências, dividindo esse presente e abrindo espaço para inserir nele o futuro, de modo que, a partir dessa ruptura, que é um ato ético-político, outras formas de ser, outros acontecimentos, outros sentidos possam ser produzidos no tempo intempestivo da criação e da invenção (Ewald, 1997). Nesse movimento, não é o caso de relacionar os humanos ao seu tempo, mas pensá-los, a cada momento, em luta contra ele.

Nessa perspectiva heterogenética, de pluricausalidade, o poder não é considerado como algo monolítico, piramidal e linear, e sim como relações de poder, uma teia de relações que compõem e atravessam todo o campo social: a vida na casa, as relações amorosas, o trabalho, normalizando e regulando existências e que, exatamente por serem relações de força, provocam táticas e estratégias de resistência "se há relações de poder em todo o campo social é porque há liberdade para todo o lado" (Foucault, 2004, p. 277). É uma concepção de poder que aponta para tecnologias positivas e deixa de lado uma relação negativa aliada da repressão, do ocultamento e do impedimento. Ao contrário: são as relações de poder que produzem saberes, corpos, subjetividade, tecnologias e instituições e são a marca do projeto genealógico desse autor.

Em suas análises, Foucault problematiza as formações políticas, procurando tornar visíveis as lutas e conflitos entre saberes e poderes, de modo a deixar claro o caráter absolutamente circunstancial das formas de ver e falar (dizer), portanto, de trabalhar, que vieram a constituir nossos modos de existência: categorizar, avaliar, interpretar. Afinal, sua proposta nos indica que, ao recusar análises abstratas e universais, a realidade do trabalho deve ser tomada como efeito de práticas em constante relação de forças: oposições e transformações sem nenhuma determinação em última instância (Veyne, 1995).

Destacamos aqui as tensões entre o normativo e o inventivo (ineliminável) que se lhe contrapõe; a ênfase na subversão tem o mérito de desnaturalizar o instituído, o que não tem o sentido de subestimar os reveses que o instituído coloca ao instituinte. Se a inventividade é ineliminável, também o são as forças que a ela se contrapõem. Considerar a irredutível potência face à gestão/instituição não é desconsiderar as despotencializações que são forjadas pela também irredutível gestão/instituição. Ao analisar a implantação de mecanismos imprescindíveis para a formação da sociedade industrial, indica-se que um aparelho de produção ou formação vai se forjando, visando fixar os corpos individuais, torná-los dóceis, examiná-los, corrigi-los e classificá-los, ligando-os ainda a um aparelho de normalização e distribuindoos no espaço social. O objetivo é construir um campo de visibilidade em torno desses corpos individuais com o mínimo de dispêndio e o máximo de eficácia. Essa ação se efetiva por meio de uma tecnologia de vigilância e de punições normalizadoras que se desenvolviam em organizações panópticas, os grandes espaços fechados: quartéis, escolas, fábricas, prisões, hospitais, orfanatos e asilos.

O controle e consumo do tempo foram alvos privilegiados por esse dispositivo disciplinar pois, para a constituição de uma sociedade industrial, era importante que o tempo dos homens fosse colocado no mercado, que 
fosse oferecido para ser comprado por um salário e que fosse transformado em força de trabalho.

Entretanto, nesses espaços de controle e vigilância, onde se entrava pela manhã e de onde se saía à noite, não somente foram produzidos corpos dóceis e normalizados. Afirmando o caráter positivo das relações de poder, séries de saberes sobre esses corpos individualizados emergiram desse campo fértil e foram utilizadas, na divisão do trabalho, para definir as capacidades e habilidades de cada trabalhador e sua alocação produtiva e adequada nas linhas de produção.

Forma-se, então, um quadro em que subjetividade, corpos e espaços urbanos foram esquadrinhados, controlados e normalizados por tecnologias cuja finalidade pode ser resumida desta forma: "Um lugar para cada coisa e cada coisa em seu lugar", caracterizando um tipo de ordenação que devia obedecer a regulamentações relacionadas ao aumento/manutenção de uma força de trabalho ativa e produtiva (Barros \& Josephson, 2007).

Em outro momento de sua obra, Foucault constrói a noção de biopoder (Foucault, 1999; Foucault, 2009), assim, nomeando esse poder bifronte composto pelos dispositivos disciplinar e biopolítico e inteiramente voltado para a expansão e conservação da vida em todas as suas modalidades, para a produção tanto de subjetividades adestradas como de formas de subjetivação que escapam. Poder que recobre toda a superfície da vida em geral, que vai do polo do corpo ao da população, mediante o jogo duplo das tecnologias da disciplina de uma parte e das tecnologias biopolíticas de outra.

Os procedimentos biopolíticos se aplicam ao homem-espécie, aos processos de conjunto e por isso se dirigem aos fenômenos populacionais. Ocupam-se das cidades, das relações entre os humanos; se substancializam nas práticas médicas higienistas, nos dados estatísticos, no controle das enfermidades, das mortes, dos nascimentos, das anomalias, na incidência dos acidentes e na constituição de estratégias de segurança no trabalho voltadas para os "erros" e "falhas" nos processos laborais, inclusive, e em tudo o mais que for relativo aos fenômenos de massa.

O biopoder bifronte é um poder que visa processos de totalização, pois estende seu controle pelos corpos e consciências, extraindo e absorvendo deles sua força para dirigi-los, regulá-los, rearticulá-los e tentar administrar a totalidade das relações sociais, dos fenômenos globais, de massa, sendo, por isso mesmo, avaliado como indispensável para o nascimento e desenvolvimento do capitalismo. Ele assegura a inserção dos corpos individuais no processo produtivo, a disciplina e o ajustamento dos elementos demográficos aos processos econômicos, a biopolítica.

A sociedade de normalização é uma sociedade em que se cruzam, conforme uma articulação ortogonal, a norma da disciplina e a norma da regulamentação. Dizer que o poder, no século XIX tomou posse da vida, dizer pelo menos que o poder, no século XIX, incumbiu-se da vida, é dizer que ele conseguiu cobrir toda a superfície que se estende do orgânico ao biológico, do corpo à população, mediante o jogo duplo das tecnologias de disciplinas, de uma parte, e das tecnologias de regulamentação, de outra (Foucault, 1999, p. 302)

Esse biopoder, atualmente aliado ao neoliberalismo, efetua-se por meio de um funcionamento que se dá segundo o eixo flexível do mercado econômico. Este será considerado como instância balizadora para a construção da verdade nas sociedades neoliberais contemporâneas de massa, amparado no axioma político da sociedade 
liberal do pós-guerra: "É preciso governar para o mercado, em vez de governar por causa do mercado" (Foucault, 2008, p. 165).

Isso implicou na expansão da esfera econômica para outras áreas que tradicionalmente ficavam fora de seu escopo, e na criação de tecnologias de governo e controle dos indivíduos coextensivas às flexíveis regras neoliberais da economia do mercado globalizado. Nesse modo de funcionamento neoliberal, surge a Teoria do Capital Humano trazendo consigo a ressignificação e a retomada da noção de Homo economicus (Foucault, 2008).

A economia, ao encampar a análise do comportamento humano, volta-se para esmiuçar a racionalidade interna desse comportamento e para o estabelecimento de estratégias que devem regular a programação das atividades individuais. Essa forma de funcionamento se dirige aos modos com que o indivíduo produz seu capital humano e ao valor desse capital, isto é, aos investimentos econômicos realizados para essa produção.

E como é formado esse capital? Pelo que o indivíduo traz de herança genética suas características inatas -, pelos valores e comportamentos oriundos de sua vida familiar, por suas relações sociais, pelas redes nas quais ele se insere, pelos cuidados com a saúde, por sua qualidade de vida, sua educação formal e pela experiência e desenvolvimento profissionais. Todas essas características, aperfeiçoadas por meio de investimentos apropriados para seu enriquecimento, compõem um capital acumulado que forma um todo com o trabalhador e é indissociável dele.

Esse Homo economicus é o homem que se utiliza das instituições colocadas no mercado de acordo com seus interesses pessoais e as exigências definidas no momento e que deve, principalmente, se manter atento aos recursos capazes de gerar vantagens competitivas por sua raridade. Nesse processo de "produção de si", a educação e a formação profissional são encaradas como um investimento que aumenta os ganhos e a produtividade, por promoverem conhecimentos e ampliarem habilidades para administrar e produzir inovações (Paiva, 2001), e se convertem em processo de modulação contínua, em que nada que é começado é terminado, porque é sem fim. De acordo com um entusiasta dessa teoria:

\begin{abstract}
A graduação não é a conclusão de um processo de conhecimento. É normalmente o fim de um estágio mais geral e preparatório e o começo de um processo mais especializado e frequentemente mais longo de aquisição de habilidade ocupacional após a entrada na força de trabalho (Mincer (1993), citado por Petrini,

Fonseca \& Porreca, 2010, p. 186)
\end{abstract}

Para a economia, nessa perspectiva, não cabe mais perguntar a quanto se compra o trabalho, o que é produzido tecnicamente, mas saber como quem trabalha utiliza os recursos de que dispõe (Foucault, 2008). Ela deve agora se colocar no lugar do trabalhador, que não é mais um objeto que oferece sua força de trabalho no mercado, para saber como ele utiliza os recursos de que dispõe, sabendo que ele é um sujeito econômico ativo, dono de uma competência, que é seu capital, máquina positiva que produz sua própria renda - fluxos de renda variáveis também em função da duração de sua capacidade de produzir, atualizar e acumular seu capital humano.

O neoliberalismo, encarnado no Homo economicus e amparado pela Teoria do Capital Humano, deslocou para o âmbito individual os problemas de emprego e fez da educação um valor econômico, um bem utilitário; trabalho e trabalhador se transmudaram em peças no jogo flexível do mercado que se expande, impondo sua forma em todas as formas de relações e de funcionamento que acontecem no corpo social. 
Em meio às políticas da vida,

às biopolíticas, modos de trabalho rotineiros, centrados na "repetição do mesmo", mesclamse a outras formas de trabalhar que exigem o indivíduo empreendedor, proativo, inovador, gestor de si, trabalhadorempresa. A lógica econômica de capital humano, a gestão

concebida como racionalização dos humanos, incita-os a serem empreendedores de si mesmos.
Em meio às políticas da vida, às biopolíticas, modos de trabalho rotineiros, centrados na "repetição do mesmo", mesclam-se a outras formas de trabalhar que exigem o indivíduo empreendedor, proativo, inovador, gestor de si, trabalhador-empresa. A lógica econômica de capital humano, a gestão concebida como racionalização dos humanos, incitaos a serem empreendedores de si mesmos. Estratégias biopolíticas nas quais os sujeitos produzem/reproduzem o discurso das competências tomadas como intrínsecas aos sujeitos flexíveis e adaptados.

O neoliberalismo aliado do biopoder, ao colocar o indivíduo como ator principal para o funcionamento econômico centrado nas exigências de mercado, nada mais faz do que repetir a lógica do Estado, a qual, segundo Foucault, se expressa por um poder que é, ao mesmo tempo, individualizante e totalizador e que produz "uma correlação permanente entre uma individualização sempre levada mais adiante e a consolidação da totalidade" (Foucault, 2004, p. 317).

Por isso, não há como acreditar que aniquilando o Estado pode-se atingir um melhor tipo de governo. O importante é tornar visível essa racionalidade governamental, é analisar os processos que estão em jogo na contemporaneidade e deixar a descoberto as relações de poder/saber, as práticas e dispositivos que sustentam e generalizam essa determinada formação política, de modo que outras conexões possam ser efetivadas. Portanto, trabalho genealógico e que podemos encarar com um ato de resistência.

Talvez, o objetivo hoje em dia não seja descobrir o que somos, mas recusar o que somos. Temos que imaginar e construir o que poderíamos ser para nos livrarmos deste 'duplo constrangimento' político, que é a simultânea individualização e totalização própria às estruturas do poder moderno (Foucault, 1995, p. 231)
Foucault (1995) nos oferece, assim, ferramentas importantes para a análise da atividade docente. As pistas que nos oferece indicam a urgência de problematizar e compartilhar os saberes produzidos por aqueles que trabalham. Há muito (incluindo as psicologias chamadas de organizacionais), deixou-se de conceber o trabalho como um lugar de repetição de regras ou cumprimento de tarefas pré-definidas por uma organização do trabalho. A perspectiva é outra: uma atenção ao presente, ao que está em curso nos processos de trabalho, ao caráter inventivo das ações humanas. "Pois, onde há poder há resistência" (Foucault, 2009, p.105).

Desde as perspectivas mais tradicionais da ergonomia da atividade, não se concebe o trabalho como mera execução, como amorfo. Necessariamente, ele se constitui como um processo de gestão de afazeres (e não afazeres). Em meio a uma execução de uma ação, há convocação do trabalhador na realização de arbitragens.

Por atividade, entendemos, a partir do referencial da clínica da atividade, como potência humana de realizar desvios criativos:

atividade, com seus desvios criativos convocam a fábrica da subjetividade a entrar em ação, como sendo o corpo invisível do trabalho, [...] que a exploração atual incide sobre este corpo invisível, controlando seu potencial inventivo e, se entendo o trabalho como uma produção desejante, entre outras, processada pelas corporizações, nome que dou aos agenciamentos, a exploração é a constante tentativa da captura do desejo, impedindo-o de singularizar, bloqueando sua natureza revolucionária (Maia, 2006, p. 200)

Desse modo, interessa-nos interrogar sobre as potencialidades atualizadas nas atividades docentes. Como, em seus processos de trabalho, os trabalhadores exercem seus afazeres? 
1Gaguejar não é tomado aqui como um erro no bem falar, uma deficiência ou um débito. A partir de Deleuze (1997), tomamos a expressão, de forma revertida, como procedimento de linguagem intencional, como um procedimento potente que interroga modos instituídos de escrever, pensar, trabalhar, enfim, de modos naturalizados de funcionamento social.

2 Virgínia é um nome fictício.
Habitar um presente do trabalho que se faz a cada instante, no concreto das experiências laborais, transformar o tempo. Aqui está a inspiração do pensamento de Foucault que nos instiga a pensar a respeito de trabalho, subjetividade, ética e contemporaneidade. Afinal, como traçarmos uma política de enfrentamento em um mundo capitalista onde o trabalho se insere em uma lógica de produção de mundos, em que o trabalho mais do que bens e serviços, produz subjetividades que alimentam o próprio capitalismo? O que nos tornamos nesse processo? Como vem se dando a apropriação das potencialidades de criação capazes de inventar outros mundos possíveis? Como resistir no presente, pelo trabalho, a tais investidas contra o poder de agir de trabalhadores? Como construir um comum que conjure processos de intimização da vida? Como fazer da atividade de trabalho um meio para transformar as instituições que o transversalizam, que o constituem? Como nos indicam Amador e Barros (2011), como criar vias para uma crítica relativa aos modos como o trabalho pode se tornar meio para fixações identitárias? Como, ao trabalhar, podemos indagar: o que estamos fazemos de nós mesmos? Que trabalho estamos operando sobre nós mesmos? Nessa direção, afirmamos uma linha de pesquisa-intervenção que toma como eixo ético-político, a afirmação de uma relação inventiva com o trabalho.

$\mathrm{Na}$ pesquisa que desenvolvemos, aproximamo-nos de uma docente de ensino superior, na tentativa de delinear modos de gestão imbricados em suas atividades. O que nos interessa nesse modo de fazer pesquisa é discutir o sentido da experiência docente e a potência de nossa abordagem conceitual metodológica a partir das indicações foucaultianas. Uma metodologia que implica determinada concepção de realidade e pauta-se nas discussões sobre o trabalho docente na atualidade que a pesquisa suscitou. Não estivemos preocupadas com a questão do método enquanto discussão acerca de procedimentos gerais e independentes das questões que o campo problemático da pesquisa foi delineando; ou ainda, em pensá-lo de forma geral, com procedimentos que seriam considerados adequados para responder à nossa questão. Não tomamos o método como um a priori da pesquisa, e sim afirmamos que ele faz parte dela, é um caminho provisório que nos ajudou nos debates que o campo nos colocava a todo instante. A pesquisa, então, ao percorrer um caminho que fomos delineando no processo, pôde suscitar outras questões, indicar impasses, sugerir novas direções e, assim, foi se desdobrando em outras questões metodológicas. O método que utilizamos, a autoconfrontação cruzada (Clot, 2006) não se fez de forma a se sedimentar, de forma a esquecer seus andaimes ou processo de construção. Método sedimentado expressa teorias reificadas, isto é, que se colocam como realidade sempre já dada sem necessidade de discussão e, uma vez aceitas essas teorias, bastaria simplesmente utilizar seus instrumentos, coletando dados como se estes fossem a própria realidade (Furlan, 2008).

Como já indicamos, nossa proposta de análise se forjou a partir do trabalho de Foucault. Instigadas pelo que esse autor nos propõe, ousamos experimentar uma clínica do trabalho docente. Uma abordagem que pode enriquecer a concepção de trabalho que temos adotado em nossas práticas, pois é da concretude mesma do trabalho cotidiano que partimos. A atenção aberta para o que acontencimentaliza no trabalho.

Nossa opção, por isso, fez-se pela escolha de uma posição narrativa, o que indica uma política de pesquisa. Como fazer gaguejar ${ }^{1} \mathrm{O}$ caso Virgínia² ${ }^{2}$ Como colocar em análise o que se produz em meio ao trabalho docente? Partimos da experiência de Virgínia, o que não significou nos voltarmos para um caso 
3 A narrativa apresentada compõe uma pesquisa mais ampla (Louzada, 2010). Em

concordância com essas questões enunciadas pela Clínica da Atividade, como apostas metodológicas,

foram convidados docentes que exercem suas atividades em IES privadas, com diferentes formações acadêmicas e diferentes experiências de docência. Esses interlocutores foram convidados a conversar sobre sua trajetória na docência, sobre as questões que avaliam como facilitadoras ou impeditivas de suas atividades de ensino. Os

docentes-parceiros desta pesquisa trabalham em diferentes IES privadas da Grande Vitória, onde são todos horistas e ministram de dez a quarenta horasaulas semanais. Possuem de dois meses a treze anos de experiência em sala de aula no ensino superior. Trabalham em uma instituição estando de dois

meses a doze anos no atual local de trabalho, sendo que três docentes trabalham em duas ou mais instituições de ensino, cinco possuem outra atividade profissional além do exercício da docência. Quase todos já estiveram trabalhando em outras instituições. individual. Estamos afirmando a dimensão transpessoal do ofício docente, sua dimensão necessariamente coletiva, pois a atividade é sempre dirigida. O procedimento narrativo indica que o caso individual é índice singular de situações que, problematizadas, mostram-se como ethos político (Benevides \& Passos, 2009). Assim, tudo adquire valor coletivo, experiência coletiva, de forma que qualquer docente nela se engaja pelo que é transpessoal do ofício em tela. Dessa forma, o caso se expressa como agenciamento coletivo de enunciação, pois, mesmo emitido por uma singularidade, não remete a um sujeito (Benevides \& Passos, 2009).

\section{Uma política de narrativa como ethos de pesquisa ${ }^{3}$ : aproximações de uma atividade}

Sexta-feira à noite. Última aula da semana, Virgínia respira aliviada antes de entrar em sala de aula. Chega carregada de materiais: livros, provas, trabalhos corrigidos e a corrigir. O corpo a relembra da semana. Foram 44 horas-aulas, para 11 turmas. Fora todos os outros compromissos profissionais, para além das duas faculdades em que trabalha. Fora o curso de mestrado em andamento, decorrente de uma necessidade de aprimoramento profissional. A aula transcorre em um misto de interesse e de agonia. O relógio parece andar mais devagar. Há um esforço para guiar a aula, para conduzir e convocar a turma. Há um esforço para manter a atenção. Esforços pactuados entre Virgínia e os alunos. Enfim, a aula termina ou termina-se com ela. Antecipa-se o fim de semana, anunciando uma enorme quantidade de afazeres/compromissos acumulados, pois, como rememora Virgínia, 44 horas-aulas semanais não significam 44 horas de trabalho, para cada hora em sala de aula, um (sobre)trabalho se presentifica.
Cansaço em Virgínia, cansaço em muitos outros. Como gerir, como preparar-se, como encher-se de ânimo para tantas horas-aulas, para tantas exigências, para um prolongado/ exaustivo uso de si? (Schwartz \& Durrive 2007).

Ao trabalhar, estão em jogo dramáticas dos usos de si (Schwartz \& Durrive 2007), nas quais está diretamente envolvida uma dinâmica: uso de si por outros e o uso de si por si. Uso de si por outros, consolidados por meio da objetivação das regras institucionais, como prazos, horários, modos prescritos de conduzir a atividade docente. Porém, por mais heterodeterminado nos usos de si por outros, há uma dimensão do uso de si por si. Há uma distância entre o trabalho prescrito pela organização do trabalho e o trabalho real; "trabalhar de outro modo está sempre presente no trabalhar como me dizem" (Schwartz \& Durrive 2007, p. 15).

Presentifica-se, nesses usos de si, um trabalho que atravessa Virgínia, a exigir sempre mais. Por que tanta carga-horária? A todo semestre ela recusa disciplinas. E, no entanto, a todo semestre é chamada a um aumento de carga horária, uma vez que há uma pressão por manutenção de um contrato mínimo de horas, sempre sujeitas a alteração conforme necessidade da instituição de ensino, com a variação da disposição de turmas em cada curso. A cada semestre, Virgínia aceita mais carga horária que poderia assumir.

Virgínia, sábado pela manhã, continua seu trabalho: coloca-se a responder às questões institucionais que se acumulam em suas caixas de e-mail. Prepara as provas para enviar para a coordenação de curso. Lança o conteúdo de suas disciplinas nas páginas institucionais disponibilizadas na internet. Reelabora uns slides para a aula de segundafeira. E as tarefas vão avançando pelo sábado à tarde. Refaz umas referências do plano de ensino, haja vista que o curso passará por 
avaliação do Ministério da Educação e tem que haver compatibilidade entre os livros que compõem a coleção da biblioteca e aqueles previstos no plano de ensino do docente. Invadindo a noite, responde ao e-mail convocando para uma reunião extra de estágio. Virgínia sente-se esgotada. Os outros e-mails ficarão sem respostas. Melhor não responder.

Uso intensivo das capacidades cognitivas e afetivas de Virgínia. Uma sensação de deserto a invade. Não tem o professor da sala ao lado para saber como ele faz, não tem outros com pares com quem conversar, em meio a goles de café. Onde estão os outros que dão sentido a suas atividades? Bem, os outros estão congelados nas exigências via e-mails, nos prazos esfriados, nos planejamentos antecipados das aulas que irão acontecer.

Inesperadamente, ela sorri ao ler um e-mail recebido de um aluno angustiado, contando uma situação ocorrida no estágio. Sorri, não pela angústia do estagiário, mas por se dar conta do seu ímpeto de responder e de sua espera de um retorno do aluno. Ali, no e-mail do aluno, um destinatário imediato de suas atividades docentes se apresenta e produz alguns sentidos para a burocracia com a qual lidou durante todo o sábado.

Para Clot (2006), todo trabalhador possui como destinatários imediatos de sua atividade a si e aos seus pares.

Na situação vivida, ela é dirigida não só pelo comportamento do sujeito ou dirigida por meio do objeto da tarefa, mas também dirigida aos outros. A atividade de trabalho é dirigida aos outros depois de ter sido destinatária da atividade destes e antes de o ser de novo. Ela é sempre resposta à atividade dos outros, eco de outras atividades. Ocorre numa corrente de atividades que constituem um elo [...]. O trabalho é portanto ainda uma atividade dirigida: atividade dirigida pelo sujeito, para o objeto, e para a atividade dos outros com mediação do gênero (Clot, 2006, p. 97)

O sorriso em Virgínia, propiciado pelo e-mail do aluno, parece um acalanto em meio ao uso intensivo de si ao realizar atividades com as quais discorda, ou, ao menos, a que não atribui significados diretos. Os sentidos disparados pelo sorriso sossega a amargura que a acompanhou durante o dia. Talvez seja o cansaço da semana, pensa ela, que o domingo consiga minimizar. Afinal, precisa descansar para que o trabalho (que não deixou de acontecer) possa continuar. Nas instituições de ensino superior privadas é comum encontrar prevista no calendário escolar a semana de prova. Um procedimento gerencial de ensino que tenta colocar todos em uma mesma regra. Demarca-se uma interferência direta no modo como o professor conduz sua disciplina: não passa por seu critério avaliar a necessidade das provas, quando será a sua realização, como ela será estruturada, quais conteúdos irão ou não compor a avaliação, pois a data é marcada à revelia de cada professor e deve ser adequada ao cronograma da disciplina disponibilizado no início do semestre em anexo ao plano de ensino.

Essa padronização das condutas avaliativas coloca em evidência meios regulatórios e disciplinares, que se traduzem em uma diminuição de autonomia docente em face de suas atividades. Virgínia sente-se engessada, presa a códigos totalizadores. Nela, uma exasperação:

O que eu percebo nas duas instituições de ensino em que trabalho é a questão do controle. Muitas vezes, a nossa docência fica engessada por conta desse controle, em que você tem de mostrar a prova que você aplica. Todas as duas instituições hoje têm o controle de verificar se o que você está dando, o conteúdo, o que você está cobrando, se está de acordo, se está no plano, como está a 
elaboração dessa prova. Até acho pertinente, mas se houvesse alguma reclamação que aquele professor específico não está fazendo uma prova de acordo com o plano, mas colocar isso como uma regra engessa. A própria prova já é uma obrigatoriedade, em uma instituição de ensino o valor da prova é 7, então, às vezes, você quer dar um trabalho, não tem essa possibilidade. As nossas formas de trabalho com o aluno estão passando por algum tipo de controle, você não pode dar um trabalho valendo 10 pontos, você tem que dar uma prova valendo 7, um trabalho valendo 3. A gente sente que esse controle está cada vez maior, e o professor acaba ocupando um lugar muito secundário. O professor fica simplesmente repetindo o conteúdo e o aluno não tem necessidade de assistir aula, por que ele tem o material via blog, via portal, o que preencheria o lugar do professor. O que eu sinto é que o professor tem perdido um pouco o seu espaço.

Uma padronização que não cessa. Controle que aciona mecanismos minuciosos que recobrem a vida, impregnando-a de regras. Não há discordância em Virgínia da necessidade de gestão, da necessidade de regras, a questão está na tentativa de estabelecer uma uniformidade e, por isso, a função de docente passa a ser de repetir conteúdos automatizados, ocupando um lugar secundário em face das decisões sobre sua atividade. Inquietação em Virgínia e em muitos outros.

As práticas de controle visam articular estratégias de vigilância e resultam em uma centralização das práticas gerenciais que interferem diretamente na relação docentediscente. Com os docentes diminuídos em termos de tomada de decisões relativas aos planejamentos prévios, horários regulamentados, ausência de autonomia para marcar a data da prova de forma mais pertinente a sua disciplina, entrega da pauta todo o final de mês, com os devidos conteúdos lançados, impossibilidade de retirar a pauta da instituição em algumas faculdades, segundo Virgínia:

os alunos acabam percebendo que eles têm um poder muito grande, muitas vezes eles nem falam com o professor, vão diretamente à coordenação, e o professor acaba fazendo o papel meio de bobo da corte, só quando você é chamado é que você tem noção do que está acontecendo. O aluno ocupa um lugar de cliente.

A educação como mercadoria, o aluno como cliente, imagens reincidentes na vida acadêmica, que ressoam em Virgínia. Os professores são convocados intensivamente a participar, a disponibilizar seu tempo, seus afetos e, por mais que participem, que contribuam, há sempre uma reunião a mais para ir, um trabalho extra a fazer, forjandose uma necessidade de concordância às cegas. Mecanismos de privatização da vida, efetivação de políticas de gestão piramidal.

Virgínia simplesmente segue aquilo que é esperado dela? Ela conhece todos os seus alunos, é capaz de dizer histórias pessoais de muitos deles. Enquanto está em sala de aula, é procurada por outros alunos de outras turmas, recorrentemente. Esquece-se das coisas facilmente, anda carregada delas e sempre encontra alunos para lembrá-la, para acompanhá-la. Ministra disciplinas técnicas, como ela mesma discorre, mas é conhecida como uma professora referência quando o assunto é ética profissional. Exige dos alunos uma fidelidade ao conteúdo ministrado, mas é paciente para explicar de novo, e de novo, e de novo. Vai de acordo com o ritmo da turma, algumas são mais rápidas, outras têm mais dificuldades na compreensão do conteúdo. E o plano de ensino? Ora, suas cargas horárias, suas delimitações, são apenas previsões, apenas um plano que não necessariamente vai ser seguido exatamente. 
Ao acompanhamos Virgínia em seus afazeres, usamos de um recurso metodológico - instrução ao sósia (Clot, 2008) -, e perguntamos: e se eu fosse substituí-la amanhã, como faria para não ser reconhecido?

Ela sorri bastante, pois sabe que não poderíamos substituí-la. Teríamos experiência na área das disciplinas que ministra? Ela topa a "brincadeira". Virgínia traz um elemento interessante: não é possível responder de modo imediato a essa pergunta! Substituir em qual turma, em qual encontro, em que momento da semana, em que momento do dia?

Penso que por uma questão do que eu vivencio nesses quatros anos, as quatro primeiras aulas são quando você consegue se dar mais, penso que a sexta aula fica prejudicada, porque já vem o seu cansaço, já vem o cansaço do aluno, então, eu penso que esse quinto e sexto horário é ingrato tanto para o professor quanto para o aluno. A quinta e a sexta aula, eu deixo para trabalhar a parte quais prática porque os alunos não precisam ver as questões teóricas. Nesse semestre, as minhas disciplinas mais práticas são nesse horário. Mas quando as disciplinas mais teóricas são nesse horário, eu sinto que o rendimento tanto o meu, quanto o do aluno não é bom. Os alunos não conseguem ficar até o final e, às vezes, o professor também dá graças a Deus que ele está indo embora, porque eu também vou sair mais cedo. Mas eu penso que isso é inerente aos professores também em outros contextos, porque a gente acaba sendo aluno em outros lugares. A primeira aula você chega com gás, chega conversando, por exemplo, a de hoje, foi uma aula teórica, mas uma aula teórica que vem carregada da minha experiência. Eu trabalho com multimídia, e eu penso que o uso dos recursos principalmente para o professor que dá aula à noite (só não pode deixar a sala escura), o multimídia é algo que chama atenção, prende atenção do aluno hoje. Nós temos hoje um perfil de aluno noturno trabalhador, de uma carga horária de 8 a 10 horas de trabalho e a gente percebe que nos dois últimos horários ele está ali fazendo um esforço sobre-humano, sobrenatural. Então, esse professor tem que trazer coisas que chamem a atenção do aluno.

Afetos saltam, brincam no ar, coloridos por microdecisões, quando o que está em questão são as experiências em sala de aula, evidenciando-se uma preocupação com os alunos, um repensar constante da prática profissional.

Ao ser interrogada sobre como começa uma aula, Virgínia discorre:

A primeira coisa é cumprimentar a todos, né? [...] Começo a falar, a recapitular o que foi feito na última aula, como eu trabalho com multimídia, eu retorno alguns slides anteriores, aquele último que penso que não tenha ficado muito claro. $E$ eu sempre falo com os alunos, principalmente aqueles em que estou dando aula pela primeira vez, se eu estiver falando muito rápido, vocês peçam para diminuir, façam um sinal para eu desacelerar, porque às vezes a gente que está falando, a gente não tem muita consciência do que está fazendo, eu tento tomar cuidado para não ser muito prolixa. Uma questão que a gente se depara, que aquele conteúdo eu dei semestre passado, estou repassando nesse semestre, chega um ponto em que aquele conteúdo que você mesmo, professor, acha que é tão simples, e para aquele aluno que está ali vendo pela primeira vez não é simples. Isso é algo que eu tento tomar muito cuidado. Que eu posso ter errado, ter feito isso como se fosse muito simples, e eu sinto isso como aluno no mestrado, o professor explica como se eu já dominasse todo aquele conhecimento. E aí isso tem me feito repensar quando os alunos me dizem, espera aí professora, está muito rápido. Eu penso que quando você passa por esse lugar, você passa a repensar sua forma de trabalho. 
Cheira a um controle que, por mais minucioso que se configure, é quebrado com aberturas à invenção. Cheira também a bons encontros, a paixões alegres. A atividade embrenhase em gestões, que não se modelam em gestões piramidais apenas. Professor gestor da atividade. Frente a um real que a coloca à prova a todo momento ela cria, mesmo que de forma ínfima. Viver no prescrito é "invivível" (Schwartz \& Durrive 2007).

Ao nos dispormos a acompanhar as trilhas da atividade, percebemos uma remodelação do trabalho, propiciado por seu desenrolar, pelos usos de si e pelo debate de normas. Virgínia atualiza usos de si no desenrolar de suas atividades docentes, pois há sempre um vazio deixado pelas normas. É preciso estar em sala, é preciso ministrar conteúdos, realizar avaliações, mas isso não é suficiente para guiar o curso da atividade. Para Schwartz (2007) nenhum trabalho ocorre sem normas antecedentes, isto é, normas anteriormente criadas, que incluem todo um conjunto de saberes e codificações acerca de determinados fazeres. É a história do ofício. Entretanto, por mais que tenham sido criadas pelos vivos, essas normas antecedentes jamais dão conta dos processos imanentes da vida. E, no exercício do trabalho, o vazio deixado pelas normas antecedentes convoca cada um a um novo fazer, a um novo exercício, a uma renormalização.

Assim, Virgínia considera crucial para o exercício da atividade: retomar a última aula, tecer exemplos; pedir retorno; conversar; modificar metodologias; agenciar um jeito específico a cada turma. Esse debate de normas caracteriza uma gestão do trabalho pelo próprio trabalhador. E a partir dessa gestão pode-se efetivamente viver (Schwartz \& Durrive 2007).

O conteúdo programático, o tempo de aula, o número de alunos por sala, não são definidos por Virgínia. Mas ao exercer suas atividades, cada uma vivencia as normas antecedentes, em função de um problema do como realizar a ação, ao mesmo tempo rotineira e nova, disparando dramas tecidos com suas histórias de vida e em seus valores, criando uma "desanonimação" de cada fazer. A atividade docente ganha nome, atividade paradoxalmente de Virgínia e fora dela, à medida que cada atividade, necessariamente renormalizada, singularizada, necessita de um terreno coletivo que lhe atribua novas significações.

Naproduçãodessanarrativa, muitasconversas aconteceram entre Virgínia e o pesquisador (Louzada, 2010). Conversas tecidas em meio ao trabalho, acompanhando-se o desenrolar da atividade. Conversas gravadas (por meio digital) e conversas gravadas no corpo. Em sua composição, utilizou-se o recurso da filmagem da entrevista, diários de campo e a estratégia de validar a narrativa através do retorno da mesma ao docente, que pode contribuir com sua escrita. Dessa forma, afirma-se um modo de pesquisar o trabalho que necessariamente passa pela aproximação ao trabalhador, e sua convocação à composição da pesquisa.

\section{Atividade como invenção em meio às políticas do comum}

Ao tomarmos a atividade, apostamos na importância de considerar as atividades humanas industriosas como um espaço de microgestões, ao lidar com as variabilidades do meio, as hierarquizações, e as trocas, apontam para virtualidades, tão múltiplas, tão porosas, entre a execução e os processos de gestão, simultâneos e processuais.

Várias abordagens sobre o trabalho (Wisner, 1994; Clot, 2006; Schwartz \& Durriver 2007), apostam, cada um a partir de um viés conceitual próprio, na capacidade dos 
humanos em inventar, gestar novos modos de trabalhar. Essa aposta pode ser um risco, à medida que tanto pode servir de "prato cheio" para os desdobramentos de modos de trabalhar no contemporâneo, com suas flexibilizações e descartabilidades, como para afirmar uma vida que não pode ser restrita a regras; pode soar com cooptação, mas esse não é o sentido ético aqui adotado a partir dos intercessores que construímos. A invenção, aqui, é tomada como diferente de criatividade e flexibilidade, e sim como uma capacidade do vivo em divergir; como potência à singularização.

Singularização preenchida por corpos e afetos, numa potência relacional, que não se restringe a um indivíduo, mas a processos gestados em coletivos. Devir comum do trabalho (Negri \& Hardt, 2005) potencializado pela imanência da atividade: em um processo de "insubordinação permanente, como o realizado e o nãorealizado, como projeto e execução, como atualização e, ao mesmo tempo, como virtualidade, instigando a pensar que a realidade do trabalho é feita do tecido da duração" (Amador, 2009, p. 37).

Insubordinação permanente na constituição de tramas coletivas, de tramas comuns:

A saber, precisamente num momento em que o comum, e não a sua imagem, está apto a aparecer na sua máxima força de afetação, e de maneira imanente, dado o novo contexto produtivo e biopolítico atual. [...] hoje o comum é o espaço produtivo por excelência. [...] O trabalho dito imaterial, a produção pós-fordista, o capitalismo cognitivo, todos eles são fruto da emergência do comum: eles todos requisitam faculdades vinculadas ao que nos é mais comum, a saber, a linguagem, e seu feixe correlato, a inteligência, os saberes, a cognição, a memória, a imaginação e, por conseguinte, a inventividade comum. [...] Mas essa dinâmica assim descrita só parcialmente corresponde ao que de fato acontece, já que ela se faz acompanhar pela apropriação do comum, pela expropriação do comum, pela privatização do comum, pela vampirização do comum empreendida pelas diversas empresas, máfias, estados, instituições, com finalidades que o capitalismo não pode dissimular, mesmo em suas versões mais rizomáticas (Pelbart, 2008, p. 34)

Virgínia e seus dramas tão/não seus. No meio do trabalho afetivo, constituindo redes com outros corpos, contraditoriamente convocada a usar seus afetos a serviço da produção e uma produção que, por ora, também produz seus afetos.

Atividades humanas industriosas que compõem uma trama imersa nos modos de trabalhar contemporâneos, em tempos biopolíticos. Convocação intensiva a favor de uma inventividade comum, cooperativa, na qual Virgínia se reconhece, e também por uma expropriação do comum, pela privatização do comum, da qual se ressentem.

Se no capitalismo contemporâneo, "na esfera biopolítica, a vida é levada a trabalhar para a produção, e a produção é levada a trabalhar para a vida" (Negri \& Hardt, 2001, p. 51), há uma potência às resistências, já que estas não se encontram mais do lado de fora, mas no próprio bojo da produção. Lembra-nos esses autores, que a produção cada vez mais articula modulações afetivas e, por isso, as resistências "deixam de ser marginais e tornam-se ativas no centro de uma sociedade que se abre em redes; os pontos individuais são singularizados em mil platôs" (Negri \& Hardt, 2001, p. 44).

Portanto, novas formas de exercícios de poder e, também, novas formas de singularização. Em redes, flexíveis e intercambiantes, o trabalho constitui-se cada vez mais como imaterial, como força de trabalho caracterizada por uma produção intelectual e comunicativa. Intensificam-se as relações de poder em torno do trabalho e, ao mesmo tempo, são ativados 
"os elementos críticos que desenvolvem o potencial de insubordinação e revolta mediante o conjunto completo de práticas trabalhistas" (Negri \& Hardt, 2001, p. 48). Trabalho imaterial, intelectual, mas não incorpóreo, porque diretamente acionado pela produtividade dos corpos e pelo valor dos afetos.

A importância de gestar a análise da atividade docente para além daquelas propiciadas pelo paradigma disciplinar/fabril implica em que essa análise precisa ser atravessada pelas relações de poder e de resistência, imbricada em seus fazeres, em seus aspectos corpóreos, afetivos e necessariamente produtivos. E essa produção encontra-se movida pela produção de mercadorias (imateriais como o "produto" impalpável da educação) e produção de subjetividades: produção de relações sociais.

Em tempos biopolíticos, as atividades docentes encontram-se em meio a mutações dos cenários educacionais, de gestão do ensino, de novos modos de trabalhar acionados no contemporâneo. Não é viável tomar a atividade docente regulada por um poder piramidal, pois ela é atravessada por regulações e instigada por mecanismos de incitação à produção. Tais mecanismos, entretanto, não são somente demarcados por regras institucionais e localizáveis. No contemporâneo, essas regulações tornam-se imateriais.

É preciso se aproximar para analisar a atividade docente em tempos de biopolíticas/ sociedade de controle: "não mais por meio de formas ideais, mas dentro do complexo da experiência" (Negri \& Hardt, 2001, p. 49).

Assim, nesse complexo da experiência, apostamos em uma gestão dos vivos, como competência produtiva dos humanos, não externas ao seu modo de trabalhar. Remetemos-nos a Clot (2006), quando este afirma que o trabalho necessariamente cria e recria aqueles que trabalham, assim como, ao trabalhar, os sujeitos imprimem suas marcas singulares. O trabalho concebe uma dimensão processual e clínica. Apostar em uma gestão como uma instância clínica, como desvio, que se constituem em meio a relações de poder, em meio à necessidade de produção de ruptura, e ousamos afirmar o trabalho em sua dimensão de criação coletiva, pública. 


\section{Ana Paula Figueiredo Louzada}

Doutora em Educação pela Universidade Federal do Espírito Santo. Docente da Universidade Federal do Espírito Santo, Vitória - ES - Brasil.

E-mail: paula-louzada@ig.com.br

\section{Maria Elizabeth Barros e Barros}

Doutora em Educação pela Universidade Federal do Rio de Janeiro. Docente da Universidade Federal do Espírito Santo, Vitória - ES - Brasil.

E-mail: betebarros@uol.com.br

\section{Silvia Vasconcelos Carvalho}

Doutora em Psicologia Social pela Universidade do Estado do Rio de Janeiro. Docente da Universidade Federal do Espírito Santo, Vitória - ES - Brasil.

E-mail: silviacj@superig.com.br

Endereço para envio de correspondência:

Rua Ricardo Figueiredo Abaurre no 33, apto. 201. Jardim Camburi, CEP: 20090-830 - Vitória, ES.

Recebido 27/06/2012, 1ạ Reformulação 22/08/2013, Aprovado 29/08/2013. 


\section{Referências}

Amador, F. A. (2009). Entre prisões da imagem, imagens da prisão: um dispositivo tecno-poético para uma clínica do trabalho. Tese de Doutorado. Programa de Pós-Graduação em Informática da Educação, Universidade Federal do Rio Grande do Sul, Porto Alegre.

Amador, F., Barros, M.E. B.(2011). Cartas a Foucault: em que estamos em vias de nos tornar em meio ao trabalho no contemporâneo? Revista Mnemosine, 7(2), 17-31.

Barros, R. D. B., \& Josephson, S. C. (2007). A invenção das massas: a psicologia entre o controle e a resistência, In A. M. Jacó-Vilela, A. A. L. Ferreira, \& F. T. Portugal (Orgs.), História da psicologia: rumos e percursos (pp. 441-462). Rio de Janeiro: Nau Editora.

Benevides, R., \& Passos, E. (2009). Por uma política da narrativa. In Passos, E. V. Kastrup, \& L. Escossia (Orgs), Pistas do método cartográfico: pesquisa-intervenção e produção de subjetividade. (pp.17-31). Porto Alegre: Sulina.

Canguilhem, G. (1990). O normal e o patológico. Rio de Janeiro: Forense Universitária.

Clot, Y. (2006). A função psicológica do trabalho. Petrópolis, RJ: Vozes.

Clot, Y. (2008). Trabalho e poder de agir. Belo Horizonte: Frabefactum.

Deleuze, G. (1997). Crítica e clínica. São Paulo: Editora 34.

Espinoza, B. (2007). Ética. Belo Horizonte: Autêntica Editora.

Ewald, F. (1997). Foucault et l'actualité. In D. Franche, S Prokhoris, \& Y. Roussel (Orgs.), Au risque de Foucault. (pp.156-167). Paris: Ed. Centre Pompidou.

Foucault, M. (1995). O sujeito e o poder. In H. Dreyfus, \& P. Rabinov. (Org.), Michel Foucault: uma trajetória filosófica. (pp.56-87). Rio de Janeiro: Editora Forense.

Foucault, M. (1999). Em defesa da sociedade. São Paulo: Martins Fontes.

Foucault, M. (2004). A ética do cuidado de si na prática da liberdade. In M. B. Motta (Org), Ditos e Escritos V: Etica, sexualidade e política. (pp. 36-54). Rio de Janeiro: Forense Universitária.

Foucault, M. (2008). O nascimento da biopolítica. São Paulo: Martins Fontes.
Foucault, M. (2009). História da sexualidade I: a vontade de saber. Rio de Janeiro: Edições Graal.

Furlan, R. (2008). A questão do método na psicologia. Psicologia em Estudo. Maringá, 13(1):25-33. doi: http://dx.doi. org/10.1590/S1413-73722008000100004

Maia, M. A. B. (2006). O corpo invisível do trabalho: cartografias dos processos de trabalho em saúde. Dissertação de Mestrado. Programa de Pós-Graduação em Psicologia, Universidade Federal Fluminense, Niterói, RJ.

Louzada, A. P. F. (2010). Crônicas de um trabalho docente: a invenção como imanente à vida. Tese de Doutorado. Programa de Pós-Graduação em Educação. Universidade Federal do Espírito Santo. Vitória, ES.

Negri, A., \& Hardt, M. (2005). Multidão. Rio de Janeiro: Record.

Negri, A., \& Hardt, M. (2011). Império. Rio de Janeiro: Record.

Paiva, V. (2001). Sobre o conceito de capital humano. Cadernos de Pesquisa, Rio de Janeiro, 113, 185-191. doi: http://dx.doi. org/10.1590/S0100-15742001000200010

Petrini, G., Fonseca, R, \& Porreca, W. (2010). Pobreza, Capital Humano, Capital Social e Familiar. Memorandum, 19, 184 197. Recuperado de http://www.fafich.ufmg.br.

Pelbart, P. P. (2008). Elementos para uma cartografia da grupalidade. In F. Saadi; S. Garcia (Org.), Próximo ato: questões da teatralidade contemporânea (pp. 33-37). São Paulo: Itaú Cultural.

Schwartz, Y., \& Durrive, L. (2007). Trabalho e ergologia: conversas sobre a atividade humana. Niterói, RJ: EdUFF.

Schwartz, Y. (2004). Ergonomia,Filosofia e Exterritorialidade. In Daniellou, François (Coord.). A Ergonomia em busca de seus princípios: debates epistemológicos. São Paulo: Edgar Blucher

Teixeira, V. D. \& Barros e Barros, M. E.(2009). Clínica da Atividade e cartografia: construindo metodologias de análise de trabalho. Psicologia e Sociedade. 21(1), 81-90. doi: http:// dx.doi.org/10.1590/S0102-71822009000100010

Veyne, P. M. (1995). Como se escreve a história: Foucault revoluciona a história. Brasília, DF: Editora Universidade de Brasília.

Wisner, A. (1994). A inteligência do trabalho: textos selecionados de ergonomia. São Paulo: Fundacentro. 